\title{
Analysis of the impact of selected factors on the effectiveness of using PCM in mobile window insulation
}

\author{
Michat Musia1 ${ }^{1, *}$ \\ ${ }^{1}$ Department of Building Engineering, Rzeszów University of Technology, Poznańska Street 2, \\ 35-084 Rzeszów, Poland
}

\begin{abstract}
This article presents the results of experimental research, carried out on the elements of vertical and internal blinds, containing phase-change material in its. The research was aimed at determining the significance of such factors as: ambient temperature, shape of profiles containing PCM and the intensity of their heating to the actual amount of energy required for complete melting of PCM Samples of aluminum profiles of various cross-sectional shapes containing commercial RT 28 phase-changing material. The author carried out the research presented below on the basis of a poly-selective orthogonal plan. The analysis was performed using the finite element method, in the Statistica 12 program. The obtained effects of the performed tests and the conducted analysis enabled an independent statistical evaluation of the factors of the approximate polynomial.
\end{abstract}

\section{Introduction}

In recent years, a noticeable trend in construction has been the desire to reduce the cost of thermal functioning of buildings. The elements of the thermal housing of the building, which may cause an increase in the above costs, are transparent partitions. These partitions, due to their nature, may cause overheating adjoining rooms in the summer and their overcooling in the winter. One of the possibilities to improve the energy efficiency of transparent partitions may be installing blinds or roller shutters containing phase change material.

The effectiveness of this solution will depend on the properties of the contained PCM, the thermal conditions prevailing in the surroundings of PCM, and the material parameters of the blinds and their shape.

The following is a paper in which the authors used phase change materials to improve the energy efficiency of transparent partitions.

In [1] Safari et al., The results of the simulation of the phase change temperatures depending on the climate in which PCM is to operate are presented. The above simulation refers to the range of thermal comfort $19-26^{\circ} \mathrm{C}$, described in more detail in [2-3]. The presented results indicate that in the case of the desire not to overheat the rooms, the

*Corresponding author: mmusial@prz.edu.pl 
most effective are PCMs with melting points of $24-28^{\circ} \mathrm{C}$. In turn, to counteract overcooling of rooms, PCMs should be used, which solidify at temperatures of $18-22^{\circ} \mathrm{C}$.

Liu et al. [4] conducted research on a roof window with one-chamber glazing in which phase-change material was applied between the panes. Modification of the window; provided its translucency and changed the physical and thermal properties. Researchers observed a phase shift in diurnal temperature changes compared to the reference window. In turn, no significant changes were observed in the values of the internal air temperature, through the use of PCM in the window construction.

In [5] Bianco, Vigna and Serra presented the results of experimental research conducted at the field tests stand in Turin. They tested polycarbonate panels, chamber, filled with polycarbonate bubbles, each polycarbonate bubble was filled with phase-changing materials (salt hydrates and mixtures of paraffins). After the tests, the authors indicated a reduction in the amount of solar radiation passing through the chambers by $40 \%$ in relation to the reference stands, a reduction in the peak temperature by $4-5^{\circ} \mathrm{C}$ and a 3 hour delay in the direction of the heat flux through the transparent partition after sunset.

Liu, Wu, Li, Zhou, Wang and Liu, in paper [6] presented the results of numerical and field tests needed to validate the above model. The study was subjected to a chamber window, double-glazed. The window was modified by selected phase-change materials with melting ranges of $14-16^{\circ} \mathrm{C}, 16-18^{\circ} \mathrm{C}, 18-20^{\circ} \mathrm{C}$, used different thicknesses of PCM $(4-50 \mathrm{~mm})$. The research was carried out during the heating season in north-eastern China. The obtained results allowed the selection of the most favorable combinations of PCM layer thickness $(12-30 \mathrm{~mm})$ and melting temperature $14-16^{\circ} \mathrm{C}$ for the considered location. The authors also indicate the scope of applicability of the obtained model, related to limiting the transmissiveness of transparent partitions with larger PCM thicknesses. This is also related to the poorer use of the PCM applied, due to the fact that fewer of it undergo a phase transformation.

The results presented by Li, Sun, Zou and Zhang in [7] present experimental research on a three-layer, two-chamber window, containing phase-changing material in the inner; and in the outer space between the panes. In addition, parallel testing of reference windows was carried out. The presented results, as in works $[5,6]$, confirm the lowering of the peak temperatures of glazing in the summer season and the limitation of the amount of heat flux transmitted through the glazing to the adjacent room. The authors of the considered configuration noted a decrease by $2.7^{\circ} \mathrm{C}$ and $5.4^{\circ} \mathrm{C}$ temperature of the inner surface of glass in the summer season and to reduce the heat flux density penetrating respectively $16.7 \%$ and $28 \%$.

Most of the scientific papers describing the thermal work of PCMs cooperating with transparent partitions refer only to the modernization of glass packages. It is also possible to effectively use the thermal capacity of phase-change materials, for example in internal window blinds. In papers [8-9] the author presented the results of field testing of mobile window insulation, which is the subject of patent application EP.15461528.0. In the above solution, one side of the blind was covered with black matte paint to increase the absorption capacity of solar energy. The author, being aware of the influence of: the shape of aluminum profiles, containing PCM, the intensity of their heating and thermal conditions occurring in the vicinity of the profiles, the actual amount of energy needed to completely melt the PCM used, decided to conduct laboratory tests to determine the relationship between the above-mentioned sizes. In order to reduce costs and shorten the research time, it was decided to perform them in accordance with the incomplete experience plan. This plan and statistical analysis were also used in the work [10-12].The author, guided by the criteria of implementation, information and efficiency, decided on the choice of the polyselective plan, orthogonal, described in more detail in [13]. 


\section{Materials and Method}

\subsection{Phase-change material}

As part of these studies, commercial phase change material RT 28 (paraffin mixture) was used, manufactured by Rubiterm $\mathrm{GmbH}$, with a melting and solidification enthalpy value between $\Delta$ Hfus $=220-225 \mathrm{~J} / \mathrm{g}$, melting point $=28^{\circ} \mathrm{C}$ and freezing point $=21^{\circ} \mathrm{C}$

\subsection{Aluminum samples}

For making samples, $25 \mathrm{~cm}$ sections of aluminum pipe with a wall thickness of $2 \mathrm{~mm}$ and an outside diameter of $40 \mathrm{~mm}$ were used. We made ten samples, two times for two samples with the following ratio of the length of the ellipse axis : $1.00 ; 0.910 ; 0.500 ; 0.393 ; 0.089$. To protect samples from loss of PCM, each of them was sealed from the bottom with epoxy resin Epidian 6, using hardener Z2.

\subsection{Measuring apparatus}

- Climatic chamber ESPEC;

- 16-channel recorder, Comet MS6D;

- energy consumption meter Volcraft 4000;

- temperature sensors PT 1000;

- camera Creative HD 720p.

\subsection{Research position}

The test stand was a climatic chamber, within which there were two identical, cylindrical tanks. In each of the two tanks there were identical electric heaters with a power of 1,000 W, connected to energy consumption meters and thermoregulators as well as samples of aluminum profiles. One of the tanks contained a sample containing phase-changing material, while in the other one an identical, empty reference sample. To monitor the temperature changes of aluminum samples and containers with water, PT 1000 sensors connected to the Comet MS6D recorder were used. In order to monitor and record the degree of phase change occurrence of samples containing PCM, a Creative HD 720p mobile camera was mounted.

The station constructed in this way allowed the author to record the amount of energy needed to keep the container in a constant temperature and melt PCM contained in the sample, and to compare the above value of energy consumed with that registered in the reference container. The difference in the energy consumption values between the PCM container and the reference container was the actual amount of energy needed to completely melt the PCM under the given conditions.

Photographs of the test stand and samples tested are presented in Figures 1-2. 


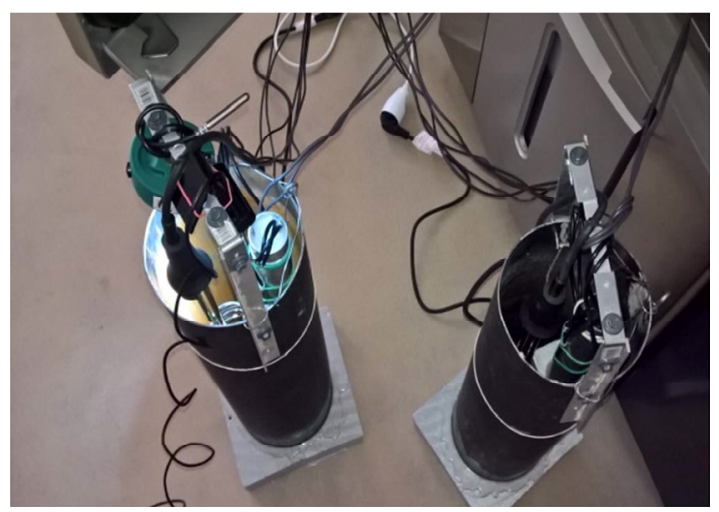

Fig. 1. Photography of laboratory position.

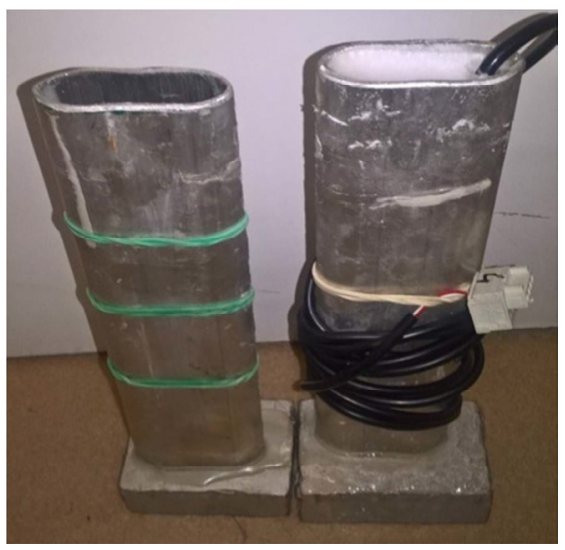

Fig. 2. Photograph of tested aluminum profiles.

\subsection{Plan of the research}

The poly-selective, orthogonal plan, was made using the STATISTICA 12 program, using the finite element method. The solution of the above plan will be the function of the object with the general formula (1):

$$
\begin{gathered}
z=b_{0}+b_{1} x_{1}+\cdots+b_{k} \ldots x_{k}+b_{12} x_{k} \ldots x_{1} x_{2}+b_{13} x_{1} x_{3}+\cdots+b_{k-1} x_{k-1} \\
+b_{11} x_{1}^{2}+\cdots+b_{k} x_{k}^{2}
\end{gathered}
$$

The above plan was made for the input and output data presented in table 1 . The scope of variability of individual input quantities were determined by the author based on the conducted field tests described [8-9].

Table 1. The scope of variability of individual input quantities.

\begin{tabular}{|c|c|}
\hline Input value & Output value \\
\hline $\begin{array}{c}\text { air temperature } \epsilon[12 ; 20] \\
\text { temperature of water } \epsilon[30 ; 60] \\
\text { shape factor } \epsilon[0.393 ; 1.0]\end{array}$ & Real amount of heat \\
\hline
\end{tabular}


The minimum number of test systems was determined based on the formula [13], for three input variables $(i=3)$ and one output one was designated as 15 and additionally two reference ones. Table 2 presents standardized and real values of independent variables.

Table 2. Experience plan.

\begin{tabular}{|c|c|c|c|c|c|c|c|}
\hline \multicolumn{4}{|c|}{ Normed values of independent variables } & \multicolumn{4}{|c|}{ Actual values of the independent variables } \\
\hline & Airtemp. & Watertemn & shape factor & & Airtemp & Water temp. & shope factor \\
\hline$\frac{1}{2}$ & $-1,00000$ & $-1,0000$ & $-1,00000$ & $\frac{1}{2}$ & $-1,00000$ & $-1,00000$ & $-1,00000$ \\
\hline$\frac{2}{3}$ & $-1,00000^{\circ}$ & $-1,0000$ & 1,00000 & $\frac{2}{3}$ & $-1,00000^{\circ}$ & $-1,00000$ & 1,00000 \\
\hline$\frac{3}{4}$ & $\begin{array}{r}-1,00000 \\
-1,00000\end{array}$ & $\begin{array}{l}1,00000 \\
1,0000\end{array}$ & $\begin{array}{r}-1,00000 \\
100000\end{array}$ & $\frac{3}{4}$ & $\begin{array}{r}-1,000000 \\
-1,00000\end{array}$ & 1,00000 & $-1,00000$ \\
\hline 5 & $\begin{array}{r}-1,000000 \\
1,00000\end{array}$ & $\begin{array}{r}1,1000000 \\
-1,0000\end{array}$ & $\begin{array}{r}1,000000 \\
-1,00000\end{array}$ & $\frac{4}{5}$ & $\begin{array}{r}-1,00000 \\
1,00000\end{array}$ & 1,00000 & 1,00000 \\
\hline 6 & 1,00000 & $-1,0000$ & $\begin{array}{l}1,00000 \\
1,0000\end{array}$ & $\frac{5}{6}$ & 1,00000 & $\begin{array}{l}-1,1,000000 \\
-1.0000\end{array}$ & $\begin{array}{r}-1,000000 \\
1,0000\end{array}$ \\
\hline 7 & 1,00000 & 1,0000 & $-1,00000$ & 7 & 1,00000 & 1,00000 & $-1,00000$ \\
\hline 8 & 1.00000 & 1.0000 & 1.00000 & 8 & 1,00000 & 1,00000 & 1,00000 \\
\hline 9 & $-1,00000$ & 0.0000 & 0,00000 & 9 & -1.00000 & 0.00000 & 0,00000 \\
\hline 10 & 1.00000 & 0.0000 & 0.00000 & 10 & 1,00000 & 0.00000 & 0.00000 \\
\hline 11 & 0.00000 & $-1,0000$ & 0.00000 & 11 & 0,00000 & -1.00000 & 0.00000 \\
\hline 12 & 0,00000 & 1,0000 & 0,00000 & 12 & 0,00000 & 1,00000 & 000000 \\
\hline 13 & 0,00000 & 0,0000 & $-1,00000$ & 13 & 0,00000 & 0,00000 & $\begin{array}{l}0,00000 \\
-1,0000\end{array}$ \\
\hline 14 & 0.00000 & 0,0000 & 1,00000 & 14 & 0.00000 & 0,00000 & 100000 \\
\hline $15(\mathrm{C})$ & 0,00000 & 0,0000 & 0,00000 & $15(\mathrm{C})$ & 0,00000 & 0,00000 & 0,00000 \\
\hline & & 0.0000 & & & 0,00000 & 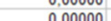 & 年, 000000 \\
\hline 17 (C) & 0.00000 & 0,0000 & 0,00000 & $\frac{76 \text { (C) }}{17 \text { (C) }}$ & 0,00000 & 0,000000 & 0,000000 \\
\hline
\end{tabular}

\section{Results}

After performing 17 experimental setups, the obtained results were supplemented with the set experimental plan. The arrangement of the plan along with received results was presented on fig. 3 .

\begin{tabular}{|c|c|c|c|c|}
\hline & Air temp. $^{1}$ & ${ }^{2}{ }^{2}$ temp. & shape factor & absorbed heat \\
\hline 1 & 12,00000 & 30,00000 & 0,393000 & 13 \\
\hline 2 & 12,00000 & 30,00000 & 1,000000 & 59 \\
\hline 3 & 12,00000 & 60,00000 & 0,393000 & 15 \\
\hline 4 & 12,00000 & 60,00000 & 1,000000 & 27 \\
\hline 5 & 20,00000 & 30,00000 & 0,393000 & 14 \\
\hline 6 & 20,00000 & 30,00000 & 1,000000 & 35 \\
\hline 7 & 20,00000 & 60.00000 & 0.393000 & 15 \\
\hline 8 & 20,00000 & 60,00000 & 1,000000 & 37 \\
\hline 9 & 11,58749 & 45,00000 & 0,500000 & 16 \\
\hline 10 & 22,41251 & 45,00000 & 0,500000 & 23 \\
\hline 11 & 17,00000 & 24,70310 & 0,500000 & 19 \\
\hline 12 & 17,00000 & 65,29690 & 0,500000 & 21 \\
\hline 13 & 17,00000 & 45,00000 & 0,089326 & 11 \\
\hline 14 & 17,00000 & 45,00000 & 0,910674 & 39 \\
\hline 15 & 17,00000 & 45,00000 & 0,500000 & 21 \\
\hline 16 & 17,00000 & 45,00000 & 0,500000 & 20 \\
\hline $17 \mid$ & 17,00000 & 45,00000 & 0,500000 & 21 \\
\hline
\end{tabular}

Fig. 3. Arrangement of the polyselection orthogonal plan supplemented with received results.

The evaluation of effects, individual independent variables and their correlation on the value of the object's function, is presented in Figures 4-5.

\begin{tabular}{|c|c|c|c|c|c|c|c|c|c|c|}
\hline & Effect & $\begin{array}{l}\text { Standard } \\
\text { error }\end{array}$ & $t(2)$ & $\mathrm{p}$ & $\begin{array}{c}-95,96 \\
\text { Lim. conf. }\end{array}$ & $\begin{array}{c}+95, \% \\
\text { Lim. conf. }\end{array}$ & Factor & $\begin{array}{c}\text { Standard } \\
\text { error }\end{array}$ & $\begin{array}{c}.95,96 \\
\text { Lim. conf. }\end{array}$ & $\begin{array}{c}+95, \% \\
\text { Lim. conf. }\end{array}$ \\
\hline Aver./const. & 26.41 & 0,324431 & 4210 & 0,000151 & 25,01960 & 27.81143 & 81552 & 0.324431 & 25,01960 & 27,81143 \\
\hline (1) & $.0,38$ & 39694 & & 50 & $-1,84596$ & 1,07721 & & & $.0,92298$ & 53860 \\
\hline Air temperture (Q) & & & & & & & & & & 00319 \\
\hline Water temperture (L) & & & & & & -3.82593 & & & 677 & 91297 \\
\hline & & & & & & & & & & \\
\hline (3) $\mathrm{sh}$ & 20.47359 & 0.27 & 85 & 0.00 & 19.27570 & 21.67147 & 10.23679 & & 9,63785 & 10.83574 \\
\hline shape factor (Q) & 2,13141 & 0.266253 & 8,0052 & 0.015249 & 0.98582 & 3.27700 & 1,06571 & 0,133126 & 0,49291 & 1,63650 \\
\hline & & & & & & 10.04771 & & & 28234 & 5.02385 \\
\hline & & & & & & & & & & $-1,44082$ \\
\hline $2 \mathrm{~L}$ rel. 3L & 7.16005 & 0.327663 & $.21,8519$ & 0.002088 & .8 .56987 & -5.75023 & $.3,58002$ & 0,163831 & 4,28493 & $\cdot 2,87511$ \\
\hline
\end{tabular}

Fig. 4. Evaluation of the effects of independent variables and their correlation on the value of the output variable. 


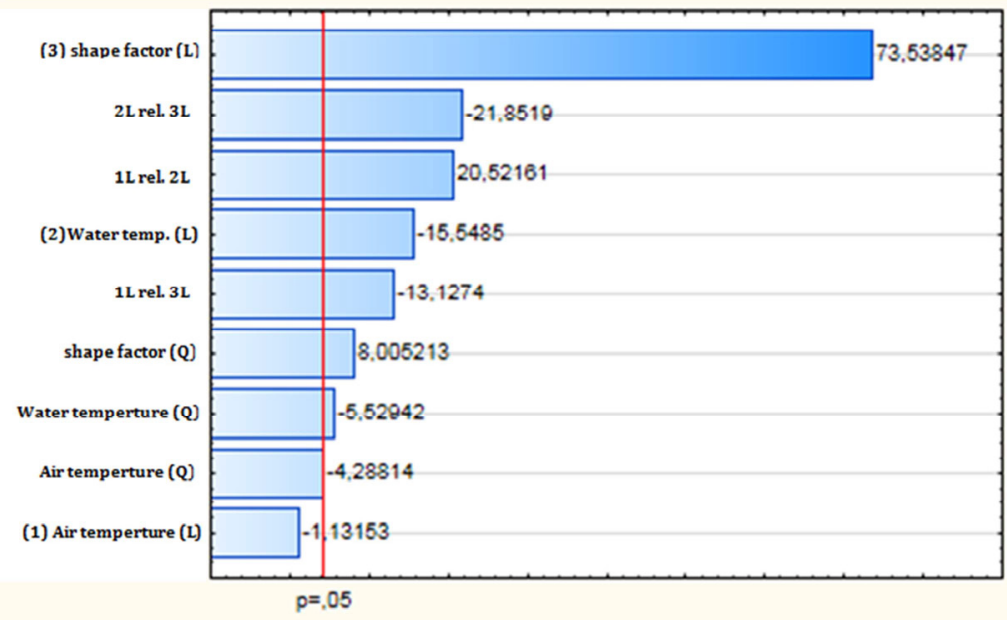

Fig. 5. Pareto chart for $95 \%$ confidence level for independent variables and their correlation.

Based on the results of the analysis presented in Figures 4-5, it was found that two ingredients, Air temperature (Q) and (L), are statically irrelevant to the assumed significance level of 5\%. In the next analysis, these components were included in the error component. Next, it was found that the next two components Water temperature $(\mathrm{Q})$ and Shape factor $(\mathrm{Q})$ are below the assumed level of significance. Other statistically significant components of analyzes are presented in Figures 6-7.

\begin{tabular}{|c|c|c|c|c|c|c|c|c|c|c|}
\hline & Effect & $\begin{array}{l}\text { Standard } \\
\text { error }\end{array}$ & $t(2)$ & $\mathrm{p}$ & $\begin{array}{l}.95,9 \% \\
\text { Lim. conf. }\end{array}$ & $\begin{array}{l}+95,96 \\
\text { Lim. conf. }\end{array}$ & Factor & $\begin{array}{l}\text { Standard } \\
\text { error }\end{array}$ & $\begin{array}{l}.95,9 \% \\
\text { Lim. conf. }\end{array}$ & $\begin{array}{c}+95,96 \\
\text { Lim. conf. }\end{array}$ \\
\hline Aver./const. & 26.00757 & 0,143665 & 181,0299 & 0,000031 & 25,38943 & 26,62571 & 26,00757 & 0,143665 & 25,38943 & 26,62571 \\
\hline (2)Water temp. (L) & $-5,28973$ & 0,340209 & $-15,5485$ & 0,004111 & $-6,75354$ & $-3,82593$ & $-2,64487$ & 0,170105 & $-3,37677$ & $-1,91297$ \\
\hline (3) shape factor (L) & 20,00505 & 0,270349 & 73,9970 & 0,000183 & 18,84183 & 21,16827 & 10,00252 & 0,135175 & 9,42092 & 10,58413 \\
\hline 1L rel. 2L & 8,30620 & 0,404754 & 20,5216 & 0,002366 & 6,56468 & 10,04771 & 4,15310 & 0,202377 & 3,28234 & 5,02385 \\
\hline 1L rel. 3L & $-4,35195$ & 0,323494 & $-13,4530$ & 0,005480 & $-5,74384$ & $-2,96007$ & $-2,17598$ & 0,161747 & $-2,87192$ & $-1,48003$ \\
\hline 2L rel, 3L & $\cdot 7,16005$ & 0,327663 & $-21,8519$ & 0,002088 & $-8,56987$ & $-5,75023$ & $-3,58002$ & 0,163831 & $-4,28493$ & $-2,87511$ \\
\hline
\end{tabular}

Fig. 6. Evaluation of the effects of statistically significant independent variables and their correlation on the value of the output variable.

(3) shape factor (L)

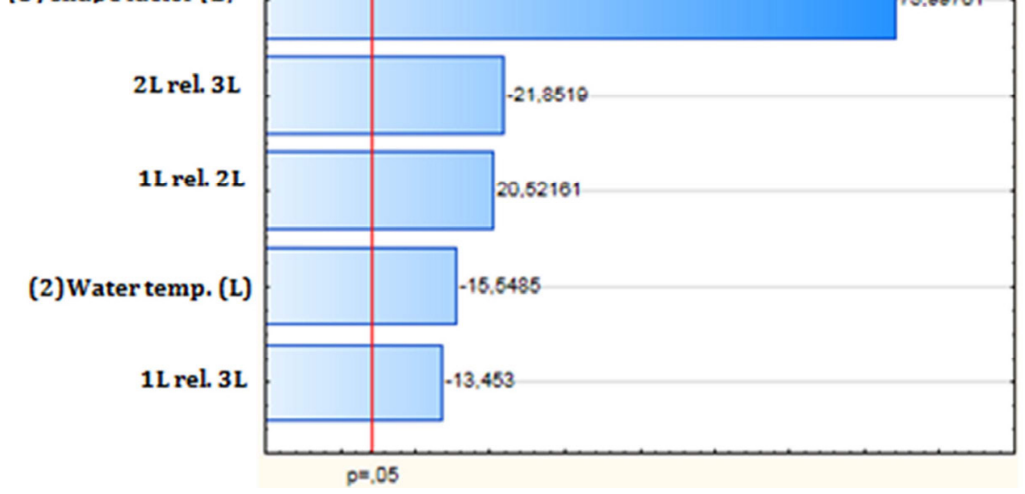

Fig. 7. Pareto chart for statistically significant independent variables and their correlation. 
Table 3 presents the answer planes with the function models describing them, made for statistically significant input variables and their correlation.

Table 3. The answer planes.

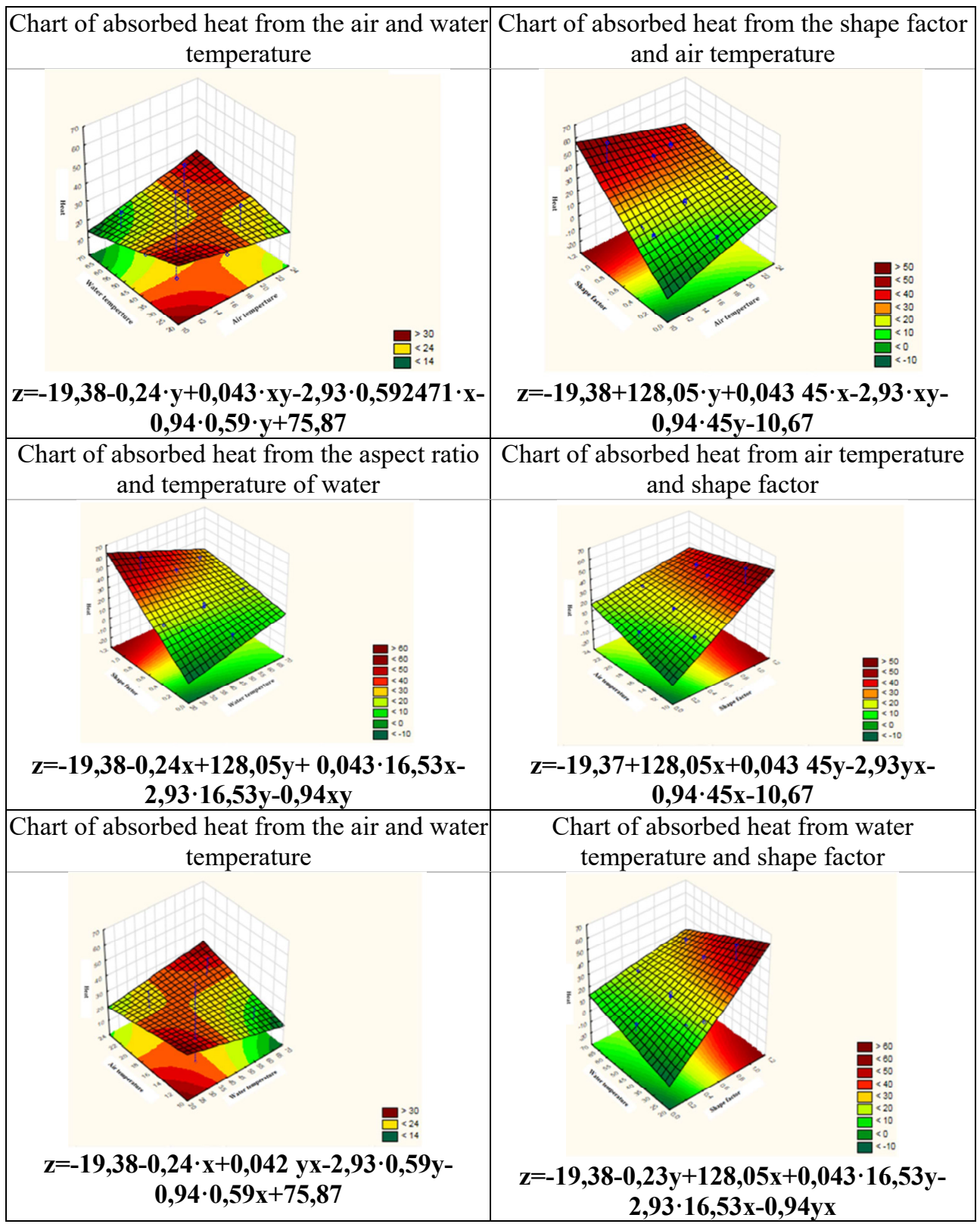

Figure 8 shows the calculated values of pure error, total error and variance for the analysis performed

Figure 9 presents the calculated regression coefficients for individual input variables and their correlation for the conducted analysis 


\begin{tabular}{|c|r|r|r|r|r|}
\cline { 2 - 6 } \multicolumn{1}{c|}{} & \multicolumn{1}{c|}{ SS } & \multicolumn{1}{c|}{ df } & \multicolumn{1}{c|}{ MS } & \multicolumn{1}{c|}{ F } & \multicolumn{1}{c|}{ P } \\
\hline (2)Water temp. (L) & 80,585 & 1 & 80,585 & 241,755 & 0,004111 \\
\hline (3) shape factor (L) & 1825,186 & 1 & 1825,186 & 5475,557 & 0,000183 \\
\hline 1L rel. 2L & 140,379 & 1 & 140,379 & 421,136 & 0,002366 \\
\hline 1L rel. 3L & 60,327 & 1 & 60,327 & 180,982 & 0,005480 \\
\hline 2L rel. 3L & 159,168 & 1 & 159,168 & 477,505 & 0,002088 \\
\hline Lack adjust & 233,917 & 9 & 25,991 & 77,972 & 0,012725 \\
\hline clear error & 0,667 & 2 & 0,333 & & \\
\hline Total sS & 2433,765 & 16 & & & \\
\hline
\end{tabular}

Fig. 8. A comparison of the calculated values of pure error, total error and variance for the conducted analysis.

\begin{tabular}{|c|c|c|c|c|c|c|}
\hline & $\begin{array}{l}\text { Regression } \\
\text { coefficient }\end{array}$ & $\begin{array}{l}\text { Standard } \\
\text { error }\end{array}$ & $t(2)$ & $p$ & $\begin{array}{c}-95, \% \\
\text { Lim. conf. }\end{array}$ & $\begin{array}{c}+95, \% \\
\text { Lim. conf. }\end{array}$ \\
\hline Aver./const. & $-19,3767$ & 1,349687 & $-14,3564$ & 0,004817 & $-25,1839$ & $-13,5694$ \\
\hline (2)Water temp. (L) & $-0,2371$ & 0,043630 & $-5,4348$ & 0,032228 & $-0,4248$ & $-0,0494$ \\
\hline (3) shape factor (L) & 128,0528 & 2,889976 & 44,3093 & 0,000509 & 115,6182 & 140,4873 \\
\hline $1 \mathrm{~L}$ rel. $2 \mathrm{~L}$ & 0,0425 & 0,001951 & 21,7881 & 0,002100 & 0,0341 & 0,0509 \\
\hline $1 \mathrm{~L}$ rel. $3 \mathrm{~L}$ & $-2,9307$ & 0,132497 & $-22,1190$ & 0,002038 & $-3,5008$ & $-2,3606$ \\
\hline $2 \mathrm{~L}$ rel. $3 \mathrm{~L}$ & -0.9379 & 0.042165 & -22.2430 & 0.002015 & $-1,1193$ & -0.7565 \\
\hline
\end{tabular}

Fig. 9. List of calculated values of regression coefficients for the conducted analysis.

\section{Conclusions}

Based on the examinations and analyzes, the author obtained the approximation polynomial formula, describing the relationship between the selected input quantities and the output value. For this polynomial, all independent variables and their statistically significant correlations were determined. Obtained results clearly showed that for the above configuration and given variability intervals, independent variables, the most important variable is the shape factor of aluminum profiles. The results of the above analysis can be used to build more complex models used to describe the thermal functioning of mobile window insulation.

\section{References}

1. M. Saffari, A. Gracia, C. Fernández, L. F. Cabeza, Appl. Energ. 202, 420-434 (2017)

2. P. Klemm, Budownictwo Ogólne, 2, (Wyd. Arkady, Warsz. 2005)

3. Dylla, Fizyka cieplna budowli w praktyce, (Wyd. PWN, Warsz. 2015)

4. C. Liu, Y. Zhou, D. Li, F. Meng, Y. Zheng, X. Liu, Energ. Build. 125, 267-275 (2016)

5. L. Bianco, I. Vigna, V. Serra, Energ. Build. 150, 608-624 (2017)

6. C. Liu, Y. Wu, D. Li, Y. Zhou, Z. Wang, X. Liu, J. Build. Eng. 11, 87-95 (2017)

7. S. Li, G. Sun, G. Zou, X. Zhang, Cit. Soci. 27, 15-22 (2016)

8. M. Musiał, M. Kaczmarzyk, JCEEA 63 (2/I/2016), 171-178 (2016)

9. L. Lichołai, M. Musiał, JCEEA, 63 (4/16), 329-338 (2016)

10. B. Dębska, L. Lichołai, Constr. Build. Mater. 124, 11-19 (2016)

11. L. Lichołai, B. Dębska, Arch. Civil Mech. Eng. 14, 466-475 (2014)

12. B. Dębska, L. Lichołai, Period. Polytech. Civ. Eng. 60, 281-287 (2016)

13. Z. Polański: Planowanie doświadczeń w technice, (PWN, Warsz, 1984) 